\title{
Overview of the power transformer park and diagnostic methods in Latvia
}

\author{
Gints Poiss, Sandra Vitolina \\ Riga Technical University \\ Department of Electrical Machines and Devices \\ Riga, Latvia \\ gints.poiss@rtu.lv, sandra.vitolina@rtu.lv
}

\begin{abstract}
Reliability of a power system depends on its equipment. As power transformers are essential elements in substations, reliability of power transmission system largely depends on their operating and technical conditions. Therefore complicated maintenance strategies are applied including various diagnostic methods and a thorough evaluation of the acquired results. Although diagnostic tests aid the evaluation of the technical condition, the risk assessment of a particular transformer is the next step in order to ensure certain reliability level. The risk assessment approach applicable for transformers in power transmission system in Latvia is proposed in this paper.
\end{abstract}

Keywords-diagnostic methods, transformer, reliability, risk assessment, life cycle

\section{INTRODUCTION}

Power transformers belong to the most important and expensive elements in a power transmission system. A transformer is a complex three-dimensional electromagnetic structure, and it is subjected to a variety of stresses - dielectric, thermal and mechanical [1] (Fig. 1). The successful functioning of transformers depends on a proper insulation system, loading and maintenance, as well as accurate design, lifetime and the quality of oil - electrical insulating medium and coolant in transformers [2]. Power transformers are electric machines with the useful lifetime of 25 - 35 years, but frequently they are used above this time, and neglecting certain fundamental requirements may lead to serious problems, if not to complete loss of the equipment. The objective of transformer diagnostics and technical condition assessment philosophy is as topical in Latvia as it is in transmission power systems in other countries.

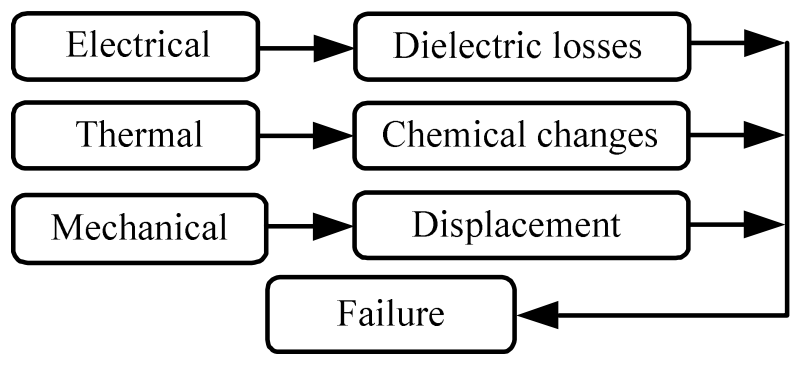

Fig. 1. Power transformer stresses which can lead to a failure
The objective of the paper is to assess the most suitable form of risk assessment for power transformers in power transmission system in Latvia. Therefore age structure of the transformer park and other specific features will be reviewed in this paper, as well as periodically performed diagnostic methods.

"Latvijas elektriskie tīkli JSC" is the company which owns the transmission system of Latvia and its task is to ensure the operation, maintenance, repairs, parametric testing, measurement and compliance assessment of the equipment installed at $330 \mathrm{kV}$ and $110 \mathrm{kV}$ substations and distribution points, dielectric testing of power safety devices etc. The company is responsible for all power transformers in the system and their diagnostic periodicity and technical condition.

The transmission system of Latvia consists of fifteen $330 \mathrm{kV}$ substations with the total autotransformer power of 3575 MVA and one hundred twenty two $110 \mathrm{kV}$ substations with the total transformer power of 4968 MVA. The power transformer park consists of $246(110 \mathrm{kV})$ power transformers and $23(330 \mathrm{kV})$ autotransformers, that are installed in substations: with one transformer, with two or three transformers, and with autotransformers [3].

The power transformer park is noticeably aged (Fig. 2). A diagram-chart has been created based on the analysis of the available data in [3]. The chart shows that the majority of transformers are in the age group of 26-40 years, but the age group of 41-50 years and more are the second largest.

In practice the lifetime of a transformer can often be extended by $20-30$ years by regular maintenance and making timely oil changes [4], but the necessity of diagnostic measurements for condition assessment also increases considerably over time.

The analysis of the power transformer park of Latvia provides the conclusion that it has a large reserve base (Fig. 3) since 90 out of 269 transformers are in so-called cold reserve, which means it is possible for the transformers to be in operating condition immediately in case of the main transformer being shut down by one of the protections or if it is shut down due to maintenance and diagnostic measurements. 


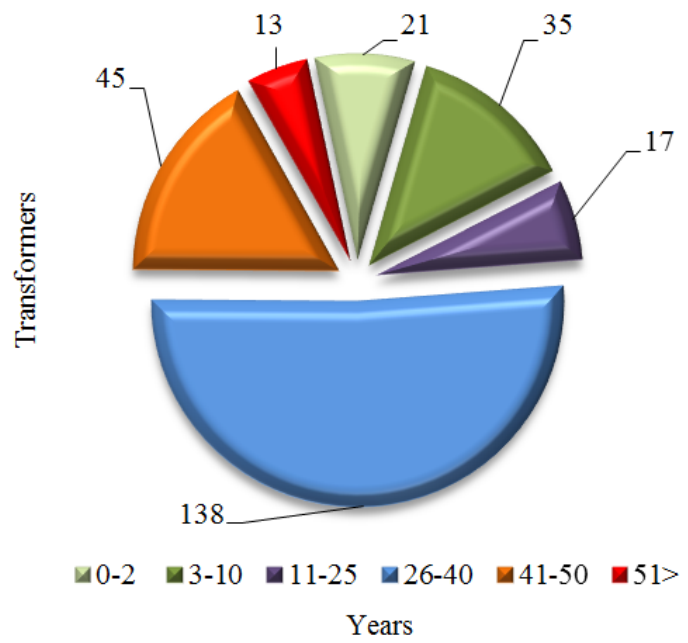

Fig. 2. Distribution of power transformers by age in 2013

Station reserve applies to the transformers which are being held at the reserve lot and can be set up if and when necessary. The proportion of these transformers depends on the power of the individual transformers and the amount of them in the power transmission system.

Contradictions arise from the reliability point of view since on one hand, the transformer reserve base is quite large. On the other hand, the park is aged - therefore gathering information about technical condition of a transformer and conducting a risk assessment are important tasks in order to ensure its continuous operation.

\section{DIAGNOSTIC METHODS AND PERIODICITY}

There are some simple suggestions to keep the transformers in a good condition: check the transformer's temperature in relation to its load, as well as the maximum temperature achieved in the relevant period; carry out regular quality measurements (electric, thermographic and chemical); check the composition of the gas in the oil; regularly check whether there is a leakage in the transformer. It is important to keep up to date with all available information about the condition of the transformer otherwise the lack of interest can create a situation where it is less expensive to replace the whole transformer [4].

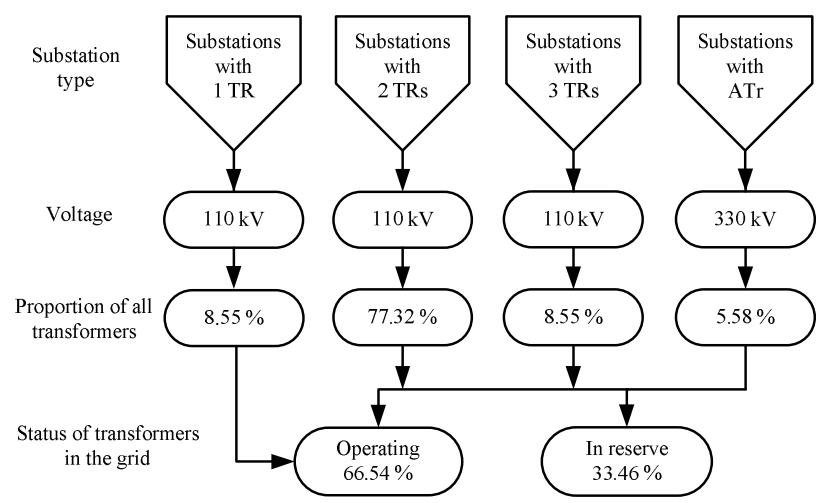

Fig. 3. Voltage, proportion and status of power transformers in different type of substations
A short overview of the diagnostic methods used in Latvia to determine the technical condition of a transformer is given below:

\section{A. Measurement of insulation resistance, absorption coefficient and polarization index}

The insulation resistance measurement, through the absorption coefficient R60"/R15" and polarization index $\mathrm{R} 1{ }^{\prime} / \mathrm{R} 10$ ', allows the estimation of the degree of moisture of the insulation of transformers [5].

\section{B. Measurement of tan $\delta$ and insulation system capacitance}

Tan $\delta$ - insulation dielectric power loss angle which is related to dielectric losses in insulation under the influence of $\mathrm{AC}$ voltage. Dielectric power loss is not a direct measure of dielectric strength but rather a diagnostic tool for monitoring the condition of solid insulation of high voltage equipment [6]. Transformer capacitance measurement is made with constant frequency - $50 \mathrm{~Hz}$ and changes of capacitance values can indicate mechanical displacements of windings.

\section{Measurement of no-load loss}

No-load loss measurements involve inserting an $\mathrm{AC}$ in the low voltage winding of the transformer while the high voltage side is open. Results of the measurements show if there is any degradation in the magnetic package, loosening of the core or a detached magnetic shunt [7].

\section{Measurement of winding resistance}

Resistance measurements across the transformer terminals provide the basis to determine the temperature and an assessment of the quality of internal connections with the transformer windings. Loose or defective connections are indicated by unusually high or unstable resistance readings [8].

\section{E. Measurement of load loss, short-ciruit and zero-sequence impedance}

The load loss represents the total losses when a rated current at a rated frequency is applied to the transformer with the winding short-circuited. Also short-circuit impedance changes will indicate irregularities in the magnetic core, winding displacement or mechanical deformation. The zerosequence impedance is the impedance measured between terminal and neutral phases when the three-phase terminals are connected together. The zero-sequence is necessary for earthfault protection and earth-fault current calculations [6].

\section{F. Dissolved Gas Analysis (DGA)}

Dissolved gas analysis is a test used as a diagnostic tool for oil-filled devices. Fault gases are produced by degradation of the insulation system, partial discharge, thermal heating and arching. Gas proportion in the transformer oil can help identifying a fault or the intensity of the fault before the equipment is irreversibly damaged [9].

In Latvia, eleven fault gases are regularly monitored for power transformer's condition assessment: hydrogen $\left(\mathrm{H}_{2}\right)$, nitrogen $\left(\mathrm{N}_{2}\right)$, oxygen $\left(\mathrm{O}_{2}\right)$, carbon monoxide $(\mathrm{CO})$, carbon dioxide $\left(\mathrm{CO}_{2}\right)$, acetylene $\left(\mathrm{C}_{2} \mathrm{H}_{2}\right)$, ethylene $\left(\mathrm{C}_{2} \mathrm{H}_{4}\right)$, methane $\left(\mathrm{CH}_{4}\right)$, ethane $\left(\mathrm{C}_{2} \mathrm{H}_{6}\right)$, propylene $\left(\mathrm{C}_{3} \mathrm{H}_{6}\right)$, propane $\left(\mathrm{C}_{3} \mathrm{H}_{8}\right)$. Ratios as $\mathrm{C}_{2} \mathrm{H}_{2} / \mathrm{C}_{2} \mathrm{H}_{4}, \mathrm{CH}_{4} / \mathrm{H}_{2}$ and $\mathrm{C}_{2} \mathrm{H}_{4} / \mathrm{C}_{2} \mathrm{H}_{6}$ are important 
and calculated when at least one fault gas reaches $90 \%$ from concentration limit.

\section{G. Insulating oil analysis}

The physical and chemical properties of the insulating oil are determined in order to evaluate the degradation of power transformer insulating oil. The properties include the colour and appearance of the oil, dielectric dissipation factor (DDF), breakdown voltage, water content, interfacial tension, oxidation stability, acidity, inhibitor content and mechanical particles [10].

\section{H. Thermography}

Unusual thermal patterns of the transformer tanks can indicate problems inside the transformer. Based on the thermal imaging results it can be ascertained which further diagnostic methods, such as DGA or insulating oil analysis, would suit best in each case. Thermography provides visual information on the technical condition of transformer elements like radiator valves, cooling fans and bushing clamps [11].

As the result of the analysis of national normative base information about periodicity of diagnostic methods used to evaluate technical condition of power transformer in the transmission system in Latvia is summarized in the Table 1.

When additional measurements are performed after the shut-down of transformers due to the protective relaying or regular maintenance, the periodicity of diagnostic methods listed in Table 1 for particular power transformer does not change.

If required, special diagnostic measurements can be designated, e.g., estimation of turns ratio, partial discharge (PD) measurement or on-load tap changer (OLTC) oscillogram.

TABLE I. DIAGNOSTIC METHOD PERIODICITY

\begin{tabular}{|c|c|c|}
\hline Diagnostic method & Device & Periodicity \\
\hline \multirow{2}{*}{$\mathrm{A}$} & $\begin{array}{r}110 \mathrm{kV} \text { transformers and } \\
330 \mathrm{kV} \text { autotransformers }\end{array}$ & 8 years \\
\hline \multirow{2}{*}{$\mathrm{B}$} & $\begin{array}{r}110 \mathrm{kV} \text { transformers and } \\
330 \mathrm{kV} \text { autotransformers }\end{array}$ & 8 years \\
\hline \multirow{2}{*}{$\mathrm{C}$} & $\begin{array}{r}110 \mathrm{kV} \text { transformers and } \\
330 \mathrm{kV} \text { autotransformers }\end{array}$ & 8 years \\
\hline \multirow{2}{*}{$\mathrm{D}$} & $\begin{array}{r}110 \mathrm{kV} \text { transformers and } \\
330 \mathrm{kV} \text { autotransformers }\end{array}$ & 8 years \\
\hline \multirow{2}{*}{$\mathrm{E}$} & $\begin{array}{r}110 \mathrm{kV} \text { transformers and } \\
330 \mathrm{kV} \text { autotransformers }\end{array}$ & 8 years \\
\hline \multirow{2}{*}{$\mathrm{F}$} & $110 \mathrm{kV}$ transformers and & 6 months \\
\hline \multirow{2}{*}{$\mathrm{G}$} & $330 \mathrm{kV}$ autotransformers & 4 years \\
\cline { 2 - 4 } & $110 \mathrm{kV}$ transformers & 2 years \\
\hline \multirow{2}{*}{$\mathrm{H}$} & $330 \mathrm{kV}$ autotransformers & 1 years \\
\cline { 2 - 4 } & $330 \mathrm{kV}$ autotransformers & 6 months \\
\hline
\end{tabular}

All diagnostic methods - electrical measurements, oil analysis, DGA and thermal imaging provide unique, seemingly unconnected results which can be viewed as:

- $\quad$ numerical values $(\Omega, \mathrm{V}, \mathrm{A}, \mathrm{W}, \mathrm{ppm})$;

- images (thermal pictures);

- diagrams (OLTC oscillogram).

Evaluating the results of any individual measurement is not enough, it is necessary to acquire and evaluate the full spectrum of results. A mathematical method for the data analysis has to be applied, and risk assessment methods are frequently used for this purpose.

\section{RISK ASSESSMENT METHODS}

Review and analysis of scientific literature allows concluding that mainly risk assessment methods of power transformers are based on probabilistic approach taking into consideration either results of one diagnostic method or complex criteria.

Therefore 2 approaches are analyzed as a representative samples:

a) Risk assessment based on the results of one diagnostic method

DGA is the easy and simple way for fault detection of power transformer and it can be carried out under the actual operation condition. Content of dissolved gases can reflect extent of insulation aging or fault of transformer. If these gases are separated from the oil sample, it can be judged by analyzing the relative quantity of gas and producing speed. Therefore risk assessment methods for power transformers that are based on the results of one diagnostic method mostly use DGA.

To identify probability of the power transformer fault key gas concentrations are used in of risk assessment based on support vector machine [12] or utilizing Monte-Carlo [13] simulation, which are a class of computational algorithms that rely on repeated random sampling to compute their results.

\section{b) Risk assessment based on complex criteria}

The most illustrative method of a risk assessment is a risk matrix (Fig. 4). The combination of likelihood and consequence will give any event a place on a risk matrix.

Most risk matrices have at least three areas:

- the low risk area (green) that indicates that the risk of an event is not high enough or it is controlled;

- the high risk area (red) which indicates the necessity for control measures to bring the likelihood and consequence down;

- the medium category (yellow) is in-between these two areas. Any event that falls in this area is usually judged to be an area that needs to be monitored or controlled so it would not elevate to high risk area. 


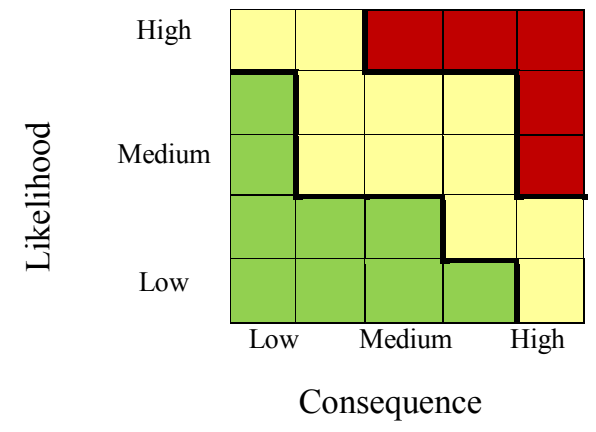

Fig. 4. An example of a risk matrix

The risk can be interpreted, for example, from insulation response of the transformer. Combined evaluation of DGA, PD, degree of polymerization (DP), water content (WC), frequency response analysis (FRA), and recovery voltage measurement (RVM) is used. Total risk is composed of the effect of individual risk factors. This risk assessment method does not predict a definite time in which the transformer will fail, but rather an increasing probability of a failure and a corresponding reduction in reliability [14].

Another way how to apply complex criteria is to provide transformer risk assessment as a single value that reflects the overall health. Multiple groups of information are used to assess health state. Transformer health indicators are, for example, design/manufacturing data, loading profile, DGA, oil dielectric quality, moisture in the insulation system and failure history [15].

\section{CONCLUSION}

Power transformer is one of the main elements of power system determining largely the reliability of electric supply. Analysis of transformers in power transmission system in Latvia showed that implementing risk assessment is a challenge since opposed factors are confronted: high proportion of aged units increasing the risk of failure considerably, and large reserve base that decrease necessity of risk evaluation since reliability of the transformer park can be maintained.

Review and analysis of scientific literature allows concluding that mainly risk assessment methods of power transformers are based on the results of performed diagnostic measurements. Since maintenance strategy, scope and periodicity of diagnostic methods are determined by transmission system operator it is not possible to apply directly risk assessment methods developed for another power system.

Due to aspect that majority of transformers in power transmission system in Latvia have served more than 20 years it is recommendable to use both short-term risk assessment and long-term risk assessment. To ensure fast and frequent evaluation a method based on DGA results is proposed to be used for the short-term risk assessment since according to Table 1 it has the highest periodicity of all diagnostic tests. For long-term risk assessment it is proposed to use risk matrix method in which diagnostic methods summarized in Table 1 serve as indicators. Mathematical model for such risk assessment approach is currently being developed.

\section{REFERENCES}

[1] S.V. Kulkarni, S.A. Khaparde, Transformer engineering. Design and practice, New York: Marcel Dekker, Inc., 2004.

[2] Paul Gill, Electrical power equipment maintenance and testing, 2nd ed., CRC Press, Taylor \& Francis Group, New York, 2009, pp. 254-255.

[3] Latvenergo group sustainability and annual report, Riga, Latvia, 2013.

[4] Transformer lifetime through maintenance and oil changes, Naphthenics magazine special issue on transformers, 2008, pp. 27-29.

[5] Marius-Constantin Popescu and Cristinel Popescu, Digital moulding of the solicitations within the dielectric of the transformers and the evaluation of life cycle of the insulation systems, Ozean Journal of Applied Sciences 3(1), 2010, pp. 41-42.

[6] Åke Carlson, Jitka Fuhr, Gottfried Schemel, Franz Wegschneider, Testing of Power transformers. Routine tests, Type tests and Special tests, 1st ed., ABB Business Area Power Transformers, 2003.

[7] André Tabernero Garcí, Power transformer maintenance. Field Testing, Unitronics, S.A., Available: http://www.unitronics.es.

[8] James H. Harlow, Electric power transformer engineering, CRC press LLC, 2004, ch. 3, sec. 6.

[9] S. Singh, M. Bandyopadhyay, Dissolved gas analysis technique for incipient fault diagnosis in power transformers, A Bibliographic Survey. IEEE Electrical. Insulation Magazine, vol.26, no. 06, pp. 41-46, 2010.

[10] K. M. Gradnik, Physical-chemical oil tests, monitoring and diagnostic of oil-filled transformers, Proceedings of 14th Int. Conf. on Dielectric Liquids, Austria, July 2002.

[11] N. Y. Utami, Y. Tamsir, A. Pharmatrisanti, H. Gumilang, B. Cahyono, R. Siregar, Evaluation condition of transformer based on infrared thermography results, 9th Int. Conf. The properties and Applications of Dielectric Materials, Harbin, China, 2009, pp. 1055-1058.

[12] Lian Chao, Lin Ma, Health assessment model of power transformer based on dissolved gas analysis by support vector machine, 6th Int. Conf. Management and Industrial Engineering (ICIII), vol.1, 2013.

[13] Huashu Liu, Lin Ma, Yuantong Gu, A Monte-Carlo simulation method for industry transformer health prediction based on dissolved gas analysis, Int. Conf. on Quality, Reliability, Risk, Maintenance, and Safety Engineering, 2013.

[14] M. Arshad, S.M. Islam, A. Khaliq, Power transformer insulation response and risk assessment, 8th International Conference on probabilistic Methods Applied to Power Systems, Ames, IA, 2004, pp. 502-505.

[15] Zhi Gao, James McCalley, William Meeker, Transformer health assessment ranking method- use of model based scoring expert system, North American Power Symposium (NAPS), Starkville, 2009, pp. 1-6. 